\title{
TRANSMISSIBILIDADE E EFEITO DE Acremonium strictum EM SEMENTES DE MILHO
}

\author{
HUDSON TEIXEIRA ${ }^{1}$ \\ JOSÉ DA CRUZ MACHADO
}

\begin{abstract}
RESUMO - Acremonium strictum é patogênico ao milho e a outras culturas, podendo causar podridão de sementes, podridão de colmos e a morte de plântulas. Trata-se de um fungo que pode interferir no vigor, estande e produtividade final das plantas. Além disso, pode ser disseminado e transmitido à progênie via sementes, ainda que não sejam conhecidas as proporções reais em que isso ocorre. Neste trabalho, avaliou-se o efeito de A. strictum nas qualidades fisiológica e sanitária de sementes e plântulas, no crescimento vegetativo e na sanidade (taxas de infecção e de transmissão) de plantas de milho em seu estádio inicial de desenvolvimento. As taxas de infecção e de transmissão do fungo
\end{abstract}

foram avaliadas usando-se a técnica da restrição hídrica, previamente desenvolvida para infectar as sementes. O meio MA (extrato de malte-ágar), suplementado com manitol para obter o potencial de água de $-1,4 \mathrm{MPa}$, foi o substrato utilizado na inoculação das sementes. Observouse que a germinação das sementes de milho foi reduzida por A. strictum em períodos de contato com a colônia fúngica acima de 72 horas. O vigor e a viabilidade potenciais das sementes de milho não foram afetados pela presença de A. strictum. Após 28 dias da semeadura, a incidência de $A$. strictum reduziu o crescimento vegetativo de plantas de milho. O fungo A. strictum, oriundo de sementes inoculadas, foi transmitido às plantas jovens de milho.

TERMOS PARA INDEXAÇÃO: Fungo, patologia de sementes, infecção, restrição hídrica.

\section{TRANSMISSIBILITY AND EFFECT OF Acremonium strictum IN MAIZE SEEDS}

\begin{abstract}
Acremonium strictum is pathogenic to seeds, stalk and seedlings of maize. It is a fungus that can interfere in the vigor, stand and final productivity of plants. In addition, it can be disseminated and transmitted through seeds to the progeny, although the real proportions of that are not well known. This study reports the effects of $A$. strictum on maize seeds and seedlings quality (germination, vigor, healthness), some vegetative growth parameters and also sanity (infection and transmission rates) of young maize plants. The transmission rate of the fungus was
\end{abstract}

evaluated using the water restriction technique. The fungus formulation was cultivated on malt extract agar medium amended with mannitol to a water potential of $-1,4 \mathrm{MPa}$. The maize seeds germination was reduced by seeds exposition to A. strictum for periods longer than 72 hours. The potentials vigor and viability were not affected by $A$. strictum. The incidence of this fungus reduced the vegetative growth of maize plants measured 28 days after sowing. The fungus originating from inoculated seeds was transmitted to young maize plants.

INDEX TERMS: Fungus, seed pathology, infection, water restriction.

\section{INTRODUÇÃO}

A condição sanitária de lotes de sementes de milho (Zea mays L.), a exemplo de outras espécies propagadas por sementes verdadeiras, é reconhecida em todo o mundo como um dos principais fatores determinantes do volume e qualidade da produção nessa cultura.
A presença de patógenos em sementes relaciona-se diretamente à baixa germinação, vigor e deterioração, uma vez que a maioria desses patógenos geralmente é capaz de ser disseminada e transmitida à progênie, causando sérios prejuízos econômicos aos produtores de sementes e aos agricultores em geral.

1. Engenheiro Agrônomo, D.Sc., Departamento de Fitopatologia, UFV, Av. P.H. Rolfs, 36571-000, Viçosa, MG.

2. Engenheiro Agrônomo, Ph.D., Departamento de Fitopatologia, UNIVERSIDADE FEDERAL DE LAVRAS/UFLA, Caixa Postal 37, 37200-000, Lavras, MG. 
Os agentes causadores de podridão de sementes, morte de plântulas e podridão de colmos de milho são considerados importantes por interferirem diretamente no vigor das plantas, estande e, conseqüentemente, na produtividade final. Entre os principais agentes causais destas enfermidades, destaque tem sido dado ao fungo Acremonium strictum W. Gams (sin.: Cephalosporium acremonium Auct. non Corda) (KOEHLER e BOEWE, 1957; BALMER, 1978; SMITH e WHITE, 1988; SHURTLEFF, 1992).

A. strictum foi primeiramente relatado como agente causal da murcha decorrente da necrose vascular do colmo do milho por Fresenius (1863) e Reddy e Holbert (1924). O patógeno também é capaz de infectar plântulas e plantas de sorgo (CHAUDHARY e MATHUR, 1986; BANDYOPADHYAY et al., 1987), podendo ser transmitido via sementes às respectivas progênies (RICHARDSON, 1990). Sabet et al. (1962) relataram A. strictum como patógeno primário do milho no Egito, causando podridão de espigas e colmos e podendo ser transmitido via sementes. Por sua vez, nos EUA, é conhecido como patógeno pouco agressivo, podendo infectar plantas de milho principalmente por intermédio de insetos e outras fontes de injúrias.

Embora seja considerado patógeno secundário no Brasil (PEREIRA, 1997; PINTO et al., 1997), A. strictum é o agente causal de uma enfermidade que tem crescido em importância, pois sua ocorrência e danos significativos têm sido relatados em outros países em área de cultivo e em sementes de milho armazenadas (DUNGAN e KOEHLER, 1944; FISHER et al., 1992).

Pouco se conhece, em termos numéricos, sobre os prejuízos causados por A. strictum à cultura de milho no Brasil, embora se acredite que o fungo já esteja bem estabelecido nas diversas regiões produtoras brasileiras.

Segundo León (1978) e Nirenberg e O’Donnell (1998), as plantas atacadas por A. strictum têm seu desenvolvimento paralisado e começam a murchar a partir das folhas superiores, produzindo espigas pequenas ou, a maioria apresenta grãos enrugados, descoloridos e malformados. O fungo A. strictum pode induzir também a morte prematura de plantas no estádio de préfloração.

Seccionando-se longitudinalmente o colmo das plantas infectadas, nota-se que os feixes vasculares apresentam coloração marrom-escura desde as raízes. A enfermidade causada por A. strictum é comum em regiões quentes, úmidas e com solos pesados. A infecção pode originar-se a partir do solo ou por meio de sementes portadoras de micélio do fungo (LEÓN, 1978).

Considera-se que A. strictum pode infectar o milho, ser prontamente disseminada e transmitida via sementes à progênie, ainda que não sejam conhecidas as proporções reais em que isso ocorre.

Dessa forma, neste trabalho avaliou-se o efeito de A. strictum nas qualidades fisiológica e sanitária de sementes e plântulas de milho, bem como parâmetros relacionados ao crescimento vegetativo e sanidade (taxas de infecção e de transmissão) de plantas de milho em fase inicial de desenvolvimento.

\section{MATERIAL E MÉTODOS}

Os ensaios foram conduzidos sob condições controladas, entre outubro de 2000 e fevereiro de 2001, nos laboratórios de Patologia de Sementes e Análise de Sementes da Universidade Federal de Lavras (MG).

\section{Determinação do perfil sanitário e fisiológico da amostra de sementes utilizada}

Para esse ensaio, utilizou-se uma amostra de sementes de milho, 'C-805' (Peneira R1), safra 99/00, produzida na região de Nova Fátima, Estado do Paraná. Essa amostra inicialmente foi submetida ao teste de sanidade (LIMONARD, 1966), que consistiu na incubação de 200 sementes, em DIC (2 repetições de 100 sementes). Pelo referido teste, a amostra apresentou a incidência de A. strictum (1\%), Fusarium verticillioides (11,5\%), Aspergillus niger (4,5\%), A. flavus (1,5\%) e Cladosporium fulvum (4\%).

$\mathrm{O}$ percentual de germinação foi determinado pela análise de 200 sementes, em DIC (2 repetições de 100 sementes), utilizando-se como substrato papel Germitest (rolo de papel), incubação a $25{ }^{\circ} \mathrm{C}$, umidade relativa (U.R.) superior a $95 \%$, e uma avaliação aos 5 dias (BRASIL, 1992). A amostra apresentou $99 \%$ de germinação.

\section{Obtenção e multiplicação de isolado de $A$. strictum}

Partindo de um isolado de A. strictum, obtido no teste de sanidade de sementes de milho descrito no item anterior, procedeu-se à multiplicação do mesmo, transferindo-se fragmentos de micélio e esporos para placas de Petri de vidro de $9 \mathrm{~cm}$ de diâmetro, contendo $20 \mathrm{~mL}$ de meio extrato de malte-ágar (MA) (SMITH e ONIONS, 1983). Esse inóculo foi mantido por 7-10 dias em estufa incubadora do tipo BOD a $20^{\circ} \mathrm{C}$ e foto- 
período de 12 h de luz negra (NUV), obtendo-se, dessa forma, colônias puras do patógeno.

\section{Inoculação de $A$. strictum em sementes de milho}

A metodologia de inoculação das sementes com o fungo foi baseada na técnica de restrição hídrica, desenvolvida para retardar a germinação das sementes de milho. Sendo assim, sementes não germinadas, mas viáveis, podem permanecer em contato com o patógeno por maior tempo, viabilizando a infecção das mesmas.

Dessa forma, foram preparadas placas de Petri de vidro de $15 \mathrm{~cm}$ de diâmetro, contendo $50 \mathrm{~mL}$ de meio MA com potencial de água de $-1,4 \mathrm{MPa}$ (Megapascal), obtido pela suplementação com manitol $(65,8$ $\mathrm{g} / \mathrm{L})$ e, em seguida, inoculado com 1,0 mL da suspensão de esporos de $A$. strictum, cuja concentração foi ajustada em $5,5 \times 10^{6}$ esporos/mL da suspensão. As colônias de $A$. strictum foram mantidas a $20^{\circ} \mathrm{C}$ e fotoperíodo de 12 h de luz NUV, em BOD.

Após 5 dias, as sementes de milho foram desinfestadas com $\mathrm{NaClO} 1 \%$ por 2 min, enxaguadas por duas vezes sucessivas em água destilada esterilizada e secas em fluxo laminar por $4 \mathrm{~h}$, sendo, então, expostas a A. strictum, em camada única, e incubadas por $24 \mathrm{~h}$, $72 \mathrm{~h}$ e $120 \mathrm{~h}$, a $20^{\circ} \mathrm{C}$, fotoperíodo de $12 \mathrm{~h}$ de luz NUV, em incubadora do tipo BOD. A testemunha $(0 \mathrm{~h})$ constou de sementes de milho desinfestadas, não-inoculadas e tratadas com o fungicida vitavax-thiram $(300 \mathrm{~mL}$ P.C./100 kg de sementes).

\section{Avaliações realizadas em sementes e plantas jovens de milho}

Procedeu-se à secagem das sementes inoculadas no ensaio anterior por dois dias à temperatura ambiente. Em seguida, as mesmas foram avaliadas quanto ao percentual de germinação, determinado em substrato de papel Germitest (rolo de papel) a $25^{\circ} \mathrm{C}$, U.R. > 95\%, após 5 dias de incubação (BRASIL, 1992). O vigor e a viabilidade potenciais foram quantificados por meio do teste de tetrazólio (DIAS e BARROS, 1995) e a incidência percentual de fungos, pelo teste de sanidade desenvolvido por Limonard (1966). Esses ensaios foram delineados em DIC, com 2 repetições de 100 sementes.

Simultaneamente, procedeu-se à semeadura em bandejas de isopor com 72 células $(5 \times 5 \times 10 \mathrm{~cm})$ a 4,0 $\mathrm{cm}$ de profundidade, utilizando-se como substrato o produto comercial esterilizado Plantmax Hortaliças ${ }^{\circledR}$. As bandejas foram mantidas em câmara de crescimento vegetal a $25 \pm 2{ }^{\circ} \mathrm{C}$ e fotoperíodo de $12 \mathrm{~h}$ de luz, sob um conjunto de três lâmpadas fluorescentes Luz do Dia. Com o objetivo de manter úmido o substrato utilizado durante todo o período experimental, fixou-se o turno de rega em 3 dias.

Nessas condições, determinou-se o estande aos 7 e 28 dias após a semeadura (d.a.s.). O índice de velocidade de emergência (I.V.E.) foi calculado pelo somatório dos quocientes resultantes entre o número total de plantas emergidas a cada dia e o número de dias decorridos da semeadura. A emissão de folhas primárias a partir do coleóptilo foi o critério adotado para se considerar uma planta de milho emergida.

Quanto aos parâmetros relacionados ao crescimento vegetativo de plantas de milho com 28 dias de idade, avaliaram-se a altura da parte aérea e o peso de matéria fresca e seca da parte aérea e de raízes. Determinou-se ainda, o índice de crescimento foliar, o qual foi obtido pela pesagem de $50 \%$ da área foliar extraída das plantas de cada parcela aos 14, 17, 20 e 23 d.a.s., por meio de corte com tesoura flambada.

Aos 28 d.a.s., foram determinadas em cada tratamento as taxas de infecção e de transmissão de $A$. strictum para a parte aérea e raiz primária de plantas de milho, bem como foi determinada a correlação entre as taxas de infecção e o percentual de incidência de $A$. strictum em sementes. Para a determinação da taxa de infecção, fragmentos de aproximadamente $3 \mathrm{~cm}$ do colmo e da raiz primária das plantas das parcelas foram seccionados transversalmente logo acima e abaixo do nível do solo, sendo, então, desinfestados inicialmente em álcool $70 \%$ e depois em $\mathrm{NaClO} 1 \%$, ambos por 1 min, enxaguados por duas vezes sucessivas em água destilada esterilizada, e incubados em meio MA a $20^{\circ} \mathrm{C}$, por 5 dias. Os fragmentos de colmo também foram seccionados longitudinalmente antes de serem submetidos à incubação.

Avaliou-se a taxa de infecção, e a partir dessa, a taxa de transmissibilidade para parte aérea e raiz primária, observando a presença de estruturas típicas de $A$. strictum em desenvolvimento sobre o meio MA.

Na determinação da taxa de transmissão (T.T.) de A. strictum das sementes para as plantas, para cada tempo de exposição, foi utilizada a seguinte metodologia:

$$
T . T .(\%)=\frac{T . I .(\%)}{I . S .(\%)} \times 100
$$

\section{Em que:}

T.I.(\%): taxa de infecção de A. strictum em fragmentos de colmos ou raízes primárias, retirados de plantas de milho com 28 dias de idade. 
I.S.(\%): incidência de A. strictum em sementes inoculadas, com base no teste de sanidade (LIMONARD, 1966).

Nos ensaios conduzidos em bandeja, o delineamento estatístico utilizado foi o de blocos ao acaso (DBC), com quatro tempos de exposição das sementes ao fungo, e cinco repetições. A parcela experimental foi constituída por 36 plantas de milho, totalizando 180 plantas para cada tratamento.As análises de variância foram realizadas utilizando o programa estatístico SiSVar e o teste de médias de Scott \& Knott $(\mathrm{P}<0,05)$. A análise de correlação linear foi realizada utilizando o programa estatístico Sanest.

\section{RESULTADOS E DISCUSSÃO}

Efeito de $A$. strictum na qualidade fisiológica de sementes e no crescimento de plantas jovens de milho.

Por meio dos resultados apresentados na Tabela 1 , observa-se que sementes não inoculadas e tratadas quimicamente $(0 \mathrm{~h}$ Tratada $)$, bem como aquelas inoculadas por $24 \mathrm{~h}$, não diferiram entre si com relação ao percentual de germinação e foram superiores às demais. Entretanto, pode-se constatar que o teste de tetrazólio, que forneceu informações acerca do vigor e viabilidade potenciais, não detectou diferença significativa entre os períodos de exposição das sementes ao fungo.

Considerando-se os resultados apresentados na tabela 1 , as sementes tratadas com vitavax-thiram apresentaram a menor incidência de A. strictum e de outros fungos, confirmando a eficiência desse tratamento. No entanto, observa-se também que, exceto para as espécies de Aspergillus, o controle total dos fungos $A$. strictum e $F$. verticillioides não ocorreu.

Segundo Carvalho (1999), a adição de manitol ao substrato de germinação das sementes de feijoeiro (BDA), no potencial de água de -1,0 MPa por até 120 $\mathrm{h}$, provocou um envigoramento (efeito priming, condicionamento osmótico ou condicionamento fisiológico) das mesmas e, por conseqüência, estimulou a emergência das plântulas formadas. No presente trabalho (Figura 1), esse efeito também foi detectado com base na determinação do índice de velocidade de emergência (I.V.E.), e as sementes que permaneceram por maior tempo sob o efeito do condicionamento osmótico, ou seja, $72 \mathrm{~h}$ e $120 \mathrm{~h}$, apresentaram maior índice de velocidade de emergência, ainda que tenham sido expostas à colonização por A. strictum. Neste ensaio, foi observado que aproximadamente $5 \%$ das sementes submetidas ao estresse hídrico por $120 \mathrm{~h}$ apresentaram protrusão radicular.

TABELA 1 - Efeito de diferentes períodos de exposição de sementes de milho a A. strictum no perfil fisiológico e sanitário de sementes. UFLA - Lavras (MG), 2001.

\begin{tabular}{lcccc}
\hline \multirow{2}{*}{ Parâmetros } & \multicolumn{4}{c}{ Períodos de exposição das sementes à A. strictum } \\
\cline { 2 - 5 } & $\mathbf{0 ~ h}$ (Tratada) & $\mathbf{2 4} \mathbf{~ h}$ & $\mathbf{7 2 ~ h}$ & $\mathbf{1 2 0} \mathbf{~ h}$ \\
\hline Germinação (\%) & $98,5 \mathrm{a}^{(*)}$ & $98,5 \mathrm{a}$ & $95,0 \mathrm{~b}$ & $91,5 \mathrm{~b}$ \\
Tetrazólio (\%) & & & \\
Vigor Potencial & $97,0 \mathrm{a}$ & $97,0 \mathrm{a}$ & $96,0 \mathrm{a}$ & $96,0 \mathrm{a}$ \\
Viabilidade Potencial & $100,0 \mathrm{a}$ & $100,0 \mathrm{a}$ & $100,0 \mathrm{a}$ & $100,0 \mathrm{a}$ \\
Incidência (\%) & & & & \\
A. strictum & $0,5 \mathrm{c}$ & $16,5 \mathrm{~b}$ & $33,5 \mathrm{a}$ & $36,0 \mathrm{a}$ \\
F. verticillioides & $2,5 \mathrm{~b}$ & $7,0 \mathrm{a}$ & $6,5 \mathrm{a}$ & $6,0 \mathrm{a}$ \\
A. flavus & $0,0 \mathrm{~b}$ & $0,0 \mathrm{~b}$ & $2,0 \mathrm{a}$ & $3,0 \mathrm{a}$ \\
A. niger & $0,0 \mathrm{a}$ & $0,0 \mathrm{a}$ & $0,0 \mathrm{a}$ & $0,5 \mathrm{a}$ \\
\hline
\end{tabular}

${ }^{(*)}$ Médias seguidas pela mesma letra nas linhas não diferem estatisticamente entre si pelo teste de Scott \& Knott $(\mathbf{P}<\mathbf{0 , 0 5})$.

Ciênc. agrotec., Lavras. V.27, n.5, p.1045-1052, set./out., 2003 
Entretanto, a baixa interferência de A. strictum no percentual germinativo das sementes de milho torna possível que um maior número de sementes fisiologicamente viáveis possa levar o inóculo desse fungo ao campo, caracterizando maior probabilidade de transmissão do fungo à progênie. Esses resultados reforçam os encontrados por diversos pesquisadores (HEPPERLY et al., 1989; PINTO et al., 1997), os quais observaram que a germinação de sementes de milho não foi prejudicada pela presença de $A$. strictum.

De acordo com os dados relativos aos estandes (Figura 1), pode-se verificar que o número médio de plântulas normais estabelecidas aos 7 d.a.s. não se alterou em função do período de exposição das sementes à A. strictum. Entretanto, com 28 dias de idade, as plantas começaram a sofrer a influência do patógeno e, assim, os tratamentos com menores percentuais de infecção mostraram-se superiores aos demais, apresentando 96,7\% de plantas normais estabelecidas, em média. Considerando do $7^{\circ}$ ao $28^{\circ}$ d.a.s., em média, foi observada uma diminuição de $6,34 \%$ no estande de plantas, e para cada tratamento, esses valores médios foram de $0,6 \%$ (0 h Tratada); 3,5\% (24 h); 11,2\% (72 h); e $10,1 \%(120 \mathrm{~h})$.
Plantas de milho com 28 dias de idade, oriundas de sementes inoculadas por períodos variáveis, apresentaram crescimento vegetativo inferior quando comparadas à testemunha (Tabela 2).

$\mathrm{Na}$ avaliação de cada aspecto do crescimento vegetativo, e comparando-se os resultados obtidos entre o tratamento-testemunha e o período de exposição das sementes por $120 \mathrm{~h}$, observaram-se os seguintes decréscimos percentuais: $40,7 \%$ (altura da parte aérea); $44,6 \%$ (peso de matéria fresca da parte aérea); $59,6 \%$ (peso de matéria fresca de raízes); $36,7 \%$ (peso de matéria seca da parte aérea); 65,8\% (peso de matéria seca de raízes) e 54,8\% (índice de crescimento foliar).

Segundo León (1978), o fungo A. strictum somente produz os sintomas mais expressivos, tais como a murcha e a seca de folhas superiores seguidas da morte prematura das plantas infectadas, ao aproximar-se do florescimento.

No presente trabalho, as plantas não foram conduzidas e avaliadas até esse estádio fenológico; no entanto, ficou demonstrado que a colonização por $A$. strictum interferiu negativamente no crescimento vegetativo de plantas jovens de milho (Tabela 2).

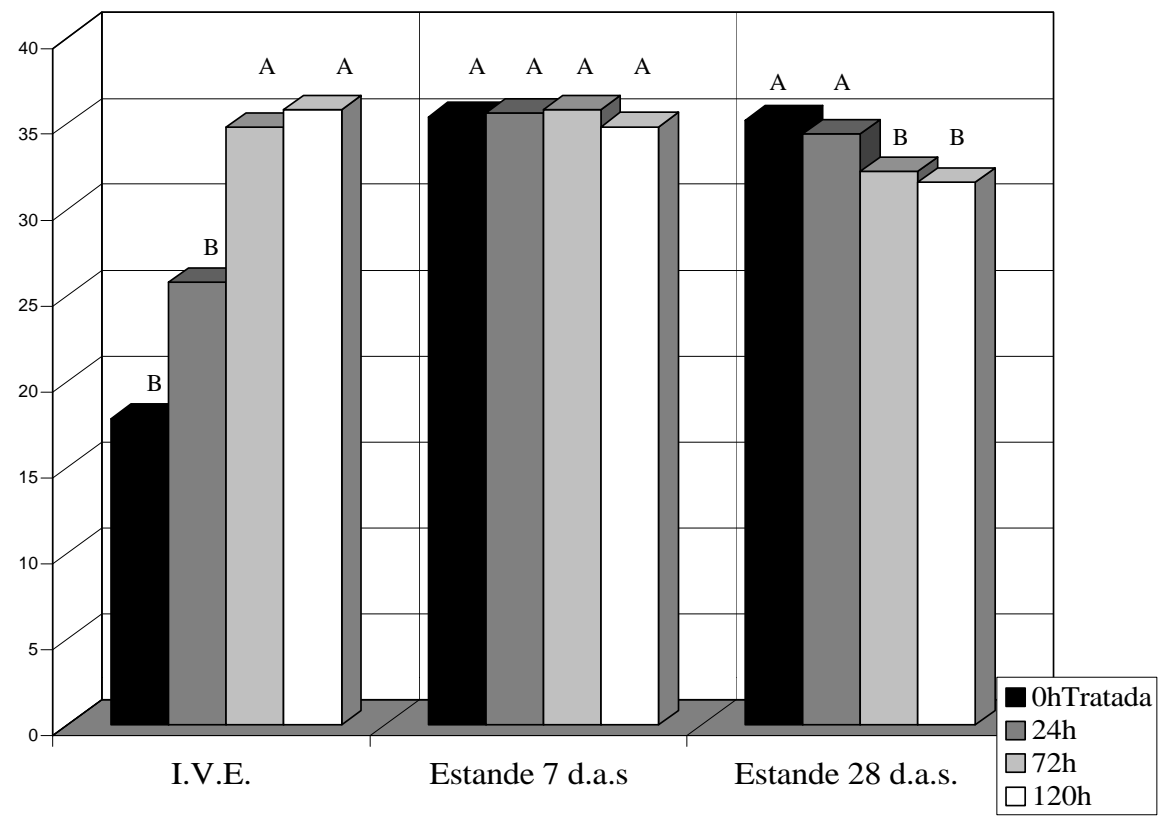

FIGURA 1 - Índice de velocidade de emergência (I.V.E.) e número de plantas estabelecidas aos 7 e aos 28 dias após a semeadura (estandes), em função de diferentes tempos de exposição de sementes de milho à A. strictum. UFLA - Lavras (MG), 2001. 
Determinação das taxas de infecção e de transmissão de $A$. strictum das sementes para as plantas de milho.

As taxas de infecção e de transmissão de $A$. strictum foram variáveis e dependentes do tempo de contato entre as sementes e o inóculo do patógeno, bem como do órgão da planta considerado (Tabela 3). Observou-se também que o tratamento com fungicida $(0 \mathrm{~h})$ controlou o patógeno presente nas sementes e não permitiu nenhuma infecção ou transmissão desse para as plantas jovens. Esse resultado confirma que o tratamento de sementes diminui a incidência de fungos, redu- zindo, conseqüentemente, a taxa de transmissão dos patógenos à progênie (NEERGAARD, 1977; TEIXEIRA et al., 1997a; MACHADO, 2000).

As maiores taxas de infecção por A. strictum, tanto na parte aérea quanto na raiz primária de plantas de milho, foram registradas quando as sementes foram expostas ao patógeno por $120 \mathrm{~h}$. Na determinação da taxa de transmissão de $A$. strictum para a parte aérea de plantas de milho com 28 dias de idade, observou-se que os tratamentos $24 \mathrm{~h}, 72 \mathrm{~h}$ e $120 \mathrm{~h}$ de exposição das sementes não diferiram entre si, apresentando uma média de $28 \%$ de fragmentos de colmos infectados pelo inóculo do patógeno, oriundo das sementes.

TABELA 2 - Efeito da exposição de sementes a A. strictum em características vegetativas de plantas de milho com 28 dias de idade. UFLA - Lavras (MG), 2001.

\begin{tabular}{lcccc}
\hline \multirow{2}{*}{ Características vegetativas } & \multicolumn{3}{c}{ Períodos de exposição das sementes à A. strictum } \\
\cline { 2 - 5 } & $\mathbf{0 ~ h}$ (Tratada) & $\mathbf{2 4 ~ h}$ & $\mathbf{7 2 ~ h}$ & $\mathbf{1 2 0} \mathbf{~ h}$ \\
\hline Altura da parte aérea (cm) & $28,78 \mathrm{a}^{(*)}$ & $22,08 \mathrm{~b}$ & $18,81 \mathrm{c}$ & $17,08 \mathrm{~d}$ \\
Peso de matéria fresca da parte aérea $(\mathrm{g})$ & $1,77 \mathrm{a}$ & $1,19 \mathrm{~b}$ & $1,10 \mathrm{~b}$ & $0,98 \mathrm{c}$ \\
Peso de matéria fresca de raízes (g) & $1,04 \mathrm{a}$ & $0,71 \mathrm{~b}$ & $0,55 \mathrm{c}$ & $0,42 \mathrm{~d}$ \\
Peso de matéria seca da parte aérea (g) & $0,090 \mathrm{a}$ & $0,071 \mathrm{~b}$ & $0,058 \mathrm{c}$ & $0,057 \mathrm{c}$ \\
Peso de matéria seca de raízes (g) & $0,079 \mathrm{a}$ & $0,044 \mathrm{~b}$ & $0,034 \mathrm{c}$ & $0,027 \mathrm{c}$ \\
Índice de crescimento foliar & $0,31 \mathrm{a}$ & $0,22 \mathrm{~b}$ & $0,13 \mathrm{c}$ & $0,14 \mathrm{c}$ \\
\hline
\end{tabular}

${ }^{(*)}$ Médias seguidas pela mesma letra nas linhas não diferem estatisticamente entre si pelo teste de Scott $\&$ Knott $(\mathbf{P}<0,05)$.

TABELA 3 - Taxas de infecção e de transmissão avaliadas em colmos e raízes primárias de plantas de milho (28 dias de idade) em diferentes períodos de exposição das sementes a A. strictum. UFLA - Lavras (MG), 2001.

\begin{tabular}{lcccc}
\hline \multirow{2}{*}{ Parâmetros } & \multicolumn{3}{c}{ Períodos de exposição das sementes à $\boldsymbol{A}$. strictum } \\
\cline { 2 - 5 } & $\mathbf{0 ~ h}$ (Tratada) & $\mathbf{2 4} \mathbf{~ h}$ & $\mathbf{7 2} \mathbf{~ h}$ & $\mathbf{1 2 0} \mathbf{~ h}$ \\
\hline Taxa de infecção (parte aérea) (\%) & $0,0 \mathrm{~d}^{(*)}$ & $4,0 \mathrm{c}$ & $9,5 \mathrm{~b}$ & $11,5 \mathrm{a}$ \\
Taxa de transmissão (parte aérea) $(\%)$ & $0,0 \mathrm{~b}$ & $24,2 \mathrm{a}$ & $28,4 \mathrm{a}$ & $31,9 \mathrm{a}$ \\
Taxa de infecção (raiz primária) $(\%)$ & $0,0 \mathrm{~d}$ & $4,5 \mathrm{c}$ & $12,5 \mathrm{~b}$ & $13,0 \mathrm{a}$ \\
Taxa de transmissão (raiz primária) $(\%)$ & $0,0 \mathrm{c}$ & $27,3 \mathrm{~b}$ & $37,3 \mathrm{a}$ & $36,1 \mathrm{a}$ \\
\hline
\end{tabular}

\footnotetext{
${ }^{(*)}$ Médias seguidas pela mesma letra nas linhas não diferem estatisticamente entre si pelo teste de Scott $\&$
} Knott $(\mathbf{P}<\mathbf{0 , 0 5})$. 
A taxa de transmissão de A. strictum via sementes para fragmentos de raízes primárias alcançou um patamar médio de $37 \%$ para os tratamentos 72 e $120 \mathrm{~h}$, superiores a $24 \mathrm{~h}$. A partir dessas observações, assumese que $A$. strictum foi transmitido à progênie do milho, além de ter sido detectado mais em raízes primárias do que em fragmentos de colmos.

Baseado em análise de correlação linear, observou-se maior correspondência entre as taxas de infecção por A. strictum em colmos e raiz primária $(98,9 \%)$, ao passo que a correlação entre a incidência do fungo em sementes e as taxas de infecção foram de $71,2 \%$ e $73,4 \%$, respectivamente. Observou-se que a probabilidade de infecção dos tecidos da planta em seu estádio inicial de desenvolvimento foi proporcional à extensão do período de contato entre o patógeno e as sementes, aspectos também relatados por Teixeira et al. (1997b).

Confirmando o relato de Koehler (1942), a recuperação de $A$. strictum em colmos e raízes primárias revelou a capacidade do fungo em se deslocar de forma ascendente e descendente na planta jovem de milho. Esse fato pode facilitar a translocação do inóculo infectivo do patógeno até a espiga via vasos condutores, bem como a conseqüiente infecção da mesma, sob condições favoráveis.

Ao contrário do que foi relatado por Casa et al. (1998), os quais estudaram a transmissão de Diplodia spp. em plantas de milho utilizando meio BSA, para as condições do presente ensaio, o meio MA permitiu o desenvolvimento e a identificação de colônias típicas de A. strictum, que, nesse substrato, desenvolveram uma coloração rosa-salmão típica, facilitando a determinação das taxas de infecção e transmissão, tanto em fragmentos de colmos quanto em raízes primárias. No presente trabalho, no entanto, ficou evidente a dificuldade em se diagnosticar em plantas vivas com até 28 dias de idade lesões típicas causadas exclusivamente por A. strictum na parte aérea ou em raízes, bem como estabelecer o grau de interferência de outros fungos no patossistema A. strictum - milho.

\section{CONCLUSÕES}

a) A. strictum reduziu a germinação de sementes de milho quando essas foram submetidas à microbiolização com o patógeno por períodos acima de 72 horas.

b) A. strictum não afetou o vigor e a viabilidade potenciais de sementes de milho, quando as mesmas foram inoculadas com esse fungo por meio da técnica de restrição hídrica, com potencial de água de -1,4 MPa. c) Parâmetros relacionados ao crescimento vegetativo de plantas de milho com 28 dias de idade foram afetados negativamente pela infecção causada por $A$. strictum, oriundo de sementes inoculadas.

d) O fungo A. strictum, oriundo de sementes inoculadas, foi transmitido às plantas jovens de milho.

\section{REFERÊNCIAS BIBLIOGRÁFICAS}

BALMER, E. Doenças do milho. In: PATERNIANI, E.; VIEGAS, G. P. Melhoramento e produção de milho no Brasil. Campinas: Fundação Cargill, 1978. p. 480-504.

BANDYOPADHYAY, R.; MUGHOGHO, L. K.; SATYANARAYANA, M. V. Systemic infection of sorghum by Acremonium strictum and its transmission through seed. Plant Disease, Saint Paul, v. 71, n. 3, p. 647-650, 1987.

BRASIL. Ministério da Agricultura e Reforma Agrária. Regras para análise de sementes. Brasília: SNAD/CLAV, 1992. 365 p.

CARVALHO, J. C. B. de. Uso da restrição hídrica na inoculação de Colletotrichum lindemuthianum em sementes de feijoeiro (Phaseolus vulgaris L.). 1999. 98 p. (Dissertação - Mestrado em Fitotecnia) - Universidade Federal de Lavras, Lavras, 1999.

CASA, R. T.; ZAMBOLIM, L.; REIS, E. Transmissão e controle de Diplódia em sementes de milho. Fitopatologia Brasileira, Brasília, v. 23, n. 4, p. 436-441, 1998.

CHAUDHARY, K. C. B.; MATHUR, S. B. Seed-borne nature of Acremonium strictum in sorghum. Indian Phytopathology, New Delhi, v. 39, n. 2, p. 296-297, 1986.

DIAS, M. C. L. de L.; BARROS, A. S. do R. Avaliação da qualidade de sementes de milho. Londrina: IAPAR, 1995. 43 p.

DUNGAN, G. H.; KOEHLER, B. Age of seed corn in relation to seed infection and yielding capacity. Journal of American Society Agronomy, Washington, v. 36, n. 5, p. 436-443, 1944.

FISHER, P. J.; PETRINI, O.; LAPPIN SCOTT, H. M. The distribution of some fungal and bacterial endophytes in mayze (Zea mays L.). New Phytologist, Cambridge, v. 122, n. 2, p. 299-305, Oct. 1992. 
FRESENIUS, J. B. G. W. Beiträge zur Mykologie. Frankfurt: Senckenberg, 1863.

HEPPERLY, P. R.; WESSEL-BEAVER, L.; CARDONACASTRO, C. Mycoflora and germination of maize seed. Jornal Agricultura Universidad Puerto Rico, Rio Piedras, v. 73, n. 2, p. 115-125, abr. 1989.

KOEHLER, B. Natural mode of entrance of fungi into maize ears and some symptoms that indicate infection. Journal of Agricultural Research, Washington, v. 64, n. 8, p. 421-442, Apr. 1942.

KOEHLER, B.; BOEWE, G. H. Causes of maize stalk in Illinois. Plant Disease, Saint Paul, v. 41, n. 6, p. 501-504, 1957.

LEÓN, C. de. Moléstias do milho: guia para sua identificação no campo. 2. ed. El Batán: CIMMYT/ CARGILL, 1978.93 p.

LIMONARD, T. A modified blotter test for seed health. Netherlands Journal of Plant Pathology, Wageningen, v. 72, p. 319-321, 1966.

MACHADO, J. C. Tratamento de sementes no controle de doenças. Lavras: LAPS/UFLA/FAEPE, 2000. $138 \mathrm{p}$.

NEERGAARD, P. Seed pathology. London: Macmillan, $1977.2 \mathrm{v}$

NIRENBERG, H. I.; O'DONNELL, K. New Fusarium species and combinations within the Gibberella fujikuroi species complex. Mycologia, New York, v. 90, n. 3, p. 434-458, 1998.

PEREIRA, O. A. P. Doenças do milho (Zea mays L.). In: KIMATI, H.; AMORIM, L.; BERGAMIN FILHO, A.; CAMARGO, L. E. A.; REZENDE, J. A. M. (Eds.). Manual de fitopatologia: doenças das plantas cultivadas. 3. ed. São Paulo: Agronômica Ceres, 1997. v. 2, p. 538-555.
PINTO, N. F. J. A.; FERNANDES, F. T.; OLIVEIRA, E. Milho (Zea mays L.): controle de doenças. In: VALE, F. X. R.; ZAMBOLIM, L. (Eds.). Controle de doenças de plantas: grandes culturas. Viçosa: UFV, 1997. v. 2, p. 821-863.

REDDY, C. S.; HOLBERT, J. R. The black-bundle disease of corn. Journal of Agricultural Research, Washington, v. 27, p. 177-205, 1924.

RICHARDSON, M. J. An annotated list of seed borne diseases. 4. ed. Zürich: ISTA, 1990. 381 p.

SABET, K. A.; HINGORANI, M. K.; SAMRA, A. S.; FAD, F. A. M. Further studies on the etiology of stalk rot of maize in the United Arab Republic. FAO Plant Protection Bulletin, Rome, v. 10, p. 132-133, 1962.

SHURTLEFF, M. C. Compendium of maize diseases. Saint Paul: American Phytopathological Society, 1992. $105 \mathrm{p}$.

SMITH, B. M.; WHITE, D. G. Disease of maize. In: SPRAGUE, G. F.; DUDLEY, Y. W. (Eds.). Maize and maize improvement. 3. ed. Madison: [s.n.], 1988. p. 687-766. (Agronomy monograph, 18).

SMITH, D.; ONIONS, A. H. S. The preservation and maintenance of living fungi. Kew: Commonwealth Mycological Institute, 1983.

TEIXEIRA, H.; VIEIRA, M. G. G. C.; MACHADO, J. C. Avaliação dos efeitos do tratamento químico e biológico de Colletotrichum gossypii South. em sementes de algodoeiro (Gossypium hirsutum L.). Ciência e Agrotecnologia, Lavras, v. 21, n. 4, p. 413-418, out./dez. 1997a.

TEIXEIRA, H.; VIEIRA, M. G. G. C.; MACHADO, J. C. Transmissibilidade e efeitos de Colletotrichum gossypii sobre sementes deslintadas de algodoeiro (Gossypium hirsutum). Fitopatologia Brasileira, Brasília, v. 22, n. 4, p. 465-471. 1997 b. 